JOURNAL OF EDUCATIONAL ADMINISTRATION AND LEADERSHIP

Volume 2 Nomor 2 Tahun 2021, Hal 168-174

ISSN: Print 2745-9691- Online 2745-9683

DOI: https://doi.org/10.24036/jeal.v2i2

Diterima Redaksi : 30-11-2021 | Selesai Revisi : 15-12--2021| Diterbitkan Online : 28-12--2021

Terbit online pada laman web jurnal: http://jeal.ppj.unp.ac.id

\title{
Keterkaitan Iklim Organisasi Dengan Faktor Lainnya
}

Sisy Maharani ${ }^{1}$, Hadiyanto $^{2}$, Rusdinal ${ }^{3}$, Sulastri ${ }^{4}$

${ }^{1234}$ Administrasi Pendidikan, Universitas Negeri Padang

Sisy Maharani ${ }^{1}$,e-mail: sisymaharani46@gmail.com

Hadiyanto², e-mail: hadiyanto@fip.unp.ac.id

Rusdinal $^{3}$, e-mail: rusdinal@fip.unp.ac.id

Sulastri4 ${ }^{4}$ e-mail: sulastrihermanto@gmail.com

\begin{abstract}
This research was made to determine what factors are influenced by organizational climate and what factors affect organizational climate. Factors influenced by organizational climate: 1) job satisfaction, 2) employee performance, 3) work motivation. Factors that influence organizational climate: 1) leadership style, 2) organizational culture, 3) work culture, 4) interpersonal communication, 5) commitment. Sources of data from this research are taken from journal articles, theses and supported by books related to organizational climate.

\section{Abstrak}

Penelitian ini dibuat untuk mengetahui faktor-faktor apa saja yang dipengaruhi oleh iklim organisasi dan faktor-faktor apa saja mempengaruhi iklim organisasi. Faktor yang dipengaruhi iklim organisasi: 1) kepuasan kerja, 2) kinerja karyawan, 3) motivasi kerja. Faktor yang mempengaruhi iklim organisasi: 1) gaya kepemimpinan, 2) budaya organisasi, 3) budaya kerja, 4) komunikasi interpersonal, 5) komitmen. Sumber data dari penelitian ini diambil dari artikel jurnal, skripsi dan didukung dengan buku-buku yang terkait dengan iklim organisasi.
\end{abstract}

Kata Kunci: faktor-faktor yang dipengaruhi iklim organisasi, faktor-faktor yang mempengaruhi iklim organisasi

How to Cite: Maharani, Sisy, Hadiyanto, Rusdinal dan Sulastri. 2021. "Study Literatur Keterkaitan Iklim Organisasi dengan Faktor lainnya". Journal Educational Administration and Leadership, Vol (N): pp. XXXX, DOI:10.24036/XXXXXXXXXX-X-XX

This is an open access article distributed under the Creative Commons 4.0 Attribution License,

which permits unrestricted use, distribution, and reproduction in any medium, provided the original work is properly cited. (C2020 by author.

\section{Pendahuluan}

Organisasi adalah suatu wadah bagi beberapa orang untuk melakukan kerjasama dalam upaya mencapai suatu tujuan yang telah ditentukan oleh organisasi tersebut. Dalam melakukan kerjasama tersebut, iklim organisasi merupakan satu hal yang perlu diperhatikan, karena kerjasama hanya dapat dilakukan dengan baik jika berada dalam iklim organisasi yang mendukung, diantaranya terjadi rasa saling percaya diantara anggota organisasi yang saling bekerjasama dalam suasana yang kondusif.

Untuk meningkatkan kualitas suatu organisasi perlu diketahui faktor-faktor yang ikut mempengaruhi orgnisasi, dan bahkan factor yang dipengaruhi oleh organisasi tersebut, salah satu faktor tersebut adalah iklim organisasi (Suliman \& B. A. Harethi, 2013). Iklim organisasi adalah suasana kerja yang dialami oleh karyawan, seperti ruang kerja yang menyenangkan, rasa aman dalam bekerja, penerangan yang memadai, sarana dan prasana yang memadai jaminan sosial yang memadai, promosi jabatan, kedudukan dan pengawasan yang memadai, Iklim organisasi merupakan persepsi anggota organisasi terhadap dimensidimensi iklim organisasi (Wirawan, 2008). Iklim organisasi mempunyai lebih kurang enam puluh enam (66) indicator (Hadiyanto, 2016) yang dapat diberikan treatment oleh pimpinan organisasi dalam rangka meningkatkan iklim tersebut untuk menjadi lebih kondusif (Syahril, Hadiyanto, Adi, \& Irsyad, 2017).

Pada literatur lain dijumpai bahwa iklim organisasi mempengaruhi atau mempunyai hubungan terhadap variabel lain contohnya:

a. Penelitian Wibisono (2011) menyebutkan iklim organisasi berpengaruh terhadap kepuasan kerja pegawai. Hasil penelitiannya menyebutkan iklim organisasi secara empiris terbukti mempunyai pengaruh signifikan terhadap kepuasan kerja pegawai. 
b. Penelitian Triastuti (2018) menyebutkan iklim organisasi berpengaruh terhadap kinerja pegawai. Hasil penelitiannya menyebutkan bahwa iklim organisasi berpengaruh positif terhadap kinerja pegawai. Artinya jika iklim organisasi ditingkatkan, maka kinerja pegawai akan meningkat pula .

Maksud dilakukan penelitian ini yaitu untuk mengetahui tentang: 1) faktor-faktor yang dipengaruhi oleh iklim organisasi, 2) faktor-faktor yang mempengaruhi iklim organisasi.

Karena terdapat faktor-faktor yang mempengaruhi, maupun yang dipengaruhi oleh iklim organisasi, serta dalam rangka memperoleh kepastian kondisi tersebut berdasarkan kajian yang telah dilakukan oleh para peneliti maupun pemerhati iklim organisasi, maka diperlukan studi literature yang lebih komprehensif untuk memastikan fakapor-faktor yang mempengaruhi maupun yang dipengaruhi oleh iklim organisasi. Studi literature ini dilakukan untuk tujuan tersebut.

\section{Metode Penelitian}

Studi yang dilaksanakan ini adalah study literature dengan menelaah artikel jurnal, skirpsi, tesis, dan buku-buku atau karya tulis lainnya yang terkait dengan rumusan masalah.. Studi ini mengkaji faktorfaktor yang mempengaruhi iklim organisasi dan faktor-faktor yang dipengaruhi oleh iklim organisasi yang telah dilakukan oleh para peneliti atau pemerhati iklim organisasi.

Data yang ditemukan dijadikan sebagai acuan dalam proses penelitian yang sesuai dengan subjek yang diteliti berdasarkan latar belakang serta rumusan masalah yaitu faktor-faktor yang mempengaruhi dan dipengaruhi oleh iklim organisasi.

3. Hasil dan Pembahasan

3.1 Hasil

Berikut ini disajikan rekapitulasi hasil penelitian oleh para peneliti terkait dengan hubungan, pengaruh, ataupun kontribusi faktor iklim organisasi terhadap faktor kepuasan kerja, dalam bentuk tabel sebagai berikut :

Tabel 1. Pengaruh Iklim organisasi terhadap kepuasan kerja

\begin{tabular}{|l|l|l|l|l|}
\hline NO & \multicolumn{1}{|c|}{ Artikel dan sumber } & Hubungan/ Pengaruh & \multicolumn{1}{|c|}{ Variebel/ Dependen } & Koefisien \\
\hline 1. & $\begin{array}{l}\text { Artikel (Susanty, 2012)(Susanty, } \\
\text { 2012)(Susanty, 2012)(Susanty, } \\
\text { 2012)(Susanty, 2012)(Susanty, } \\
\text { 2012)(Etty Susanty, 2012) }\end{array}$ & Iklim Organisasi & Kepuasan kerja & 0,0024 \\
\hline 2. & Artikel (Liana, 2012) & & & \\
\hline 3. & Artikel (Sari, 2009) & Iklim Organisasi & Kepuasan Kerja & 0,135 \\
\hline 4. & Artikel (Surachim, 2008) & Iklim Organisasi & Kepuasan Kerja & 0,714 \\
\hline 5. & Artikel (Hermawan, 2016) & Iklim Organisasi & Kepuasan Kerja & 0,630 \\
\hline 6. & Artikel (Rahmawati \& Supartha, 2015) & Iklim Organisasi & Kepuasan Kerja & 0,518 \\
\hline 7. & $\begin{array}{l}\text { Artikel (Nabilah, Tewal, \& Trang, } \\
\text { 2017) }\end{array}$ & Iklim Organisasi & Kepuasan Kerja & 0,485 \\
\hline 8. & Artikel (Subawa \& Surya, 2017) & Iklim Organisasi & Kepuasan Kerja & 0,71 \\
\hline 9. & Artikel (Mahendra \& Subudi, 2019) & Iklim Organisasi & Kepuasan Kerja & 0,338 \\
\hline 10. & $\begin{array}{l}\text { Artikel (Lagonah, Pio, \& Kaunang, } \\
\text { 2016) }\end{array}$ & Iklim Organisasi & Kepuasan Kerja & 0,565 \\
\hline
\end{tabular}

Dari hasil penelataan artikel penelitian terseub ti atas dapat dipahami bahwa iklim organisasi mempunya hubungan atau pengaruh terhadap kepuasan kerja, mesipun dengan besaran koefisien yang berbeda-beda. Namun demikian secara umum dapat dikatakan bahwa iklim organisasi merupakan faktor yang mempengaruhi atau berhubungan dengan kepuasan kerja.

Berikut ini disajikan rekapitulasi hasil penelitian oleh para peneliti terkait dengan hubungan, pengaruh, ataupun kontribusi faktor iklim organisasi terhadap faktor kinerja karyawan, dalam bentuk tabel sebagai berikut :

Tabel 2.Pengaruh Iklim organisasi terhadap kinerja karyawan

\begin{tabular}{|l|l|l|c|c|}
\hline NO & \multicolumn{1}{|c|}{ Artikel dan Sumber } & \multicolumn{1}{|c|}{$\begin{array}{c}\text { Hubungan/ } \\
\text { Pengaruh }\end{array}$} & $\begin{array}{c}\text { Variebel } \\
\text { Dependen }\end{array}$ & $\begin{array}{c}\text { Koefisie } \\
n\end{array}$ \\
\hline 1. & $\begin{array}{l}\text { Artikel (Abdillah, Anita, \& Anugerah, } \\
\text { 2017) }\end{array}$ & Iklim Organisasi & Kinerja Karyawan & 0,260 \\
\hline
\end{tabular}


Sisy Maharani ${ }^{1}$, Hadiyanto $^{2}$, Rusdinal ${ }^{3}$, Sulastri ${ }^{4}$ Keterkaitan Iklim Organisasi Dengan Faktor Lainnya

\begin{tabular}{|l|l|l|l|l|}
\hline NO & \multicolumn{1}{|c|}{ Artikel dan Sumber } & \multicolumn{1}{|c|}{$\begin{array}{c}\text { Hubungan/ } \\
\text { Pengaruh }\end{array}$} & \multicolumn{1}{|c|}{$\begin{array}{c}\text { Variebel } \\
\text { Dependen }\end{array}$} & $\begin{array}{c}\text { Koefisie } \\
n\end{array}$ \\
\hline 2. & Artikel (Janah, Akbar, \& Yetti, 2019) & Iklim Organisasi & Kinerja Karyawan & 0,442 \\
\hline 3. & Artikel (Liana, 2012) & Iklim Organisasi & Kinerja Karyawan & 0,135 \\
\hline 4. & $\begin{array}{l}\text { Artikel (Maria Rini Kustrianingsih, } \\
\text { Maria Magdalena Minarsih, 2016) }\end{array}$ & Iklim Organisasi & Kinerja Karyawan & 0,238 \\
\hline 5. & $\begin{array}{l}\text { Artikel (Ni Luh Putu Suarningsih, } \\
\text { 2013) }\end{array}$ & Iklim Organisasi & Kinerja Karyawan & 0,308 \\
\hline 6. & $\begin{array}{l}\text { Artikel (Radianto, Ari. Sunuharyo, } \\
\text { 2017) }\end{array}$ & Iklim Organisasi & Kinerja Karyawan & \\
\hline 7. & Artikel (Pamungkas \& Jabar, 2014) & Iklim Organisasi & Kinerja Karyawan & 0,077 \\
\hline
\end{tabular}

Dari hasil penelataan artikel penelitian terseub ti atas dapat dipahami bahwa iklim organisasi mempunya hubungan atau pengaruh terhadap kepuasan kerja, mesipun dengan besaran koefisien yang berbeda-beda. Namun demikian secara umum dapat dikatakan bahwa iklim organisasi merupakan faktor yang mempengaruhi atau berhubungan dengan kepuasan kerja.

Berikut ini disajikan rekapitulasi hasil penelitian oleh para peneliti terkait dengan hubungan, pengaruh, ataupun kontribusi faktor iklim organisasi terhadao faktor motivasi kerja, dalam bentuk tabel sebagai berikut :

Tabel 3. Pengaruh Iklim organisasi terhadap motivasi kerja

\begin{tabular}{|l|l|l|l|l|}
\hline NO & \multicolumn{1}{|c|}{ Aetikel dan Sumber } & $\begin{array}{c}\text { Hubungan/ } \\
\text { Pengaruh }\end{array}$ & $\begin{array}{c}\text { Variebel } \\
\text { Dependen }\end{array}$ & Koefisien \\
\hline 1. & Artikel (Pratiwi, 2016) & Iklim Organisasi & Motivasi Kerja & \\
\hline 2. & Artikel (Wahyudi \& Dewi, 2019) & Iklim Organisasi & Motivasi Kerja & 1,269 \\
\hline
\end{tabular}

Berikut ini disajikan rekapitulasi hasil penelitian oleh para peneliti terkait dengan hubungan, pengaruh, ataupun kontribusi faktor gaya kepemimpinan terhadap iklim organisasi, dalam bentuk tabel sebagai berikut :

Tabel 4. Pengaruh Gaya Kepemimpinan terhadap Iklim Organisasi

\begin{tabular}{|l|l|l|l|l|}
\hline NO & \multicolumn{1}{|c|}{ Artikel dan Sumber } & \multicolumn{1}{|c|}{$\begin{array}{c}\text { Hubungan/ } \\
\text { Pengaruh }\end{array}$} & $\begin{array}{c}\text { Variabel } \\
\text { dependen }\end{array}$ & Koefisien \\
\hline 1. & $\begin{array}{l}\text { Artikel (Salianto \& Lubis, } \\
\text { 2014) }\end{array}$ & Gaya kepemimpinan spiritual & Iklim organisasi & \\
\hline 2. & $\begin{array}{l}\text { Artikel (Ni Komang Enny } \\
\text { Trisnayanti, 2017) }\end{array}$ & Gaya Kepemimpinan Demokratis & Iklim Organisasi & 0,586 \\
\hline 3. & $\begin{array}{l}\text { Artikel (Amri, Abidin, \& } \\
\text { Nurmayanti, 2017) }\end{array}$ & $\begin{array}{l}\text { Gaya Kepemimpinan } \\
\text { Transformasional }\end{array}$ & Iklim Organisasi & 0,465 \\
\hline
\end{tabular}

Berikut ini disajikan rekapitulasi hasil penelitian oleh para peneliti terkait dengan hubungan, pengaruh, ataupun kontribusi faktor budaya organisasi terhadap iklim organisasi, dalam bentuk tabel sebagai berikut :

Tabel 5. Pengaruh Budaya Organisasi terhadap Iklim Organisasi

\begin{tabular}{|l|l|l|l|l|}
\hline NO & \multicolumn{1}{|c|}{ Sumber } & \multicolumn{1}{|c|}{$\begin{array}{c}\text { Hubungan/ } \\
\text { Pengaruh }\end{array}$} & $\begin{array}{r}\text { Variabel } \\
\text { dependen }\end{array}$ & Koefisien \\
\hline 1. & $\begin{array}{l}\text { Artikel (Salianto \& Lubis, } \\
\text { 2014) }\end{array}$ & Budaya organisasi & Iklim organisasi & \\
\hline 2. & $\begin{array}{l}\text { Artikel (Widyo Aryanto, Siti } \\
\text { Astuti, \& Kumadji, 2019) }\end{array}$ & Budaya Organisasi & Iklim Organisasi & 1,834 \\
\hline
\end{tabular}

Berikut ini disajikan rekapitulasi hasil penelitian oleh para peneliti terkait dengan hubungan, pengaruh, ataupun kontribusi faktor budaya kerja terhadap iklim organisasi, dalam bentuk tabel sebagai berikut :

Tabel 6. Pengaruh Budaya Kerja terhadap Iklim Organisasi 
Sisy Maharani ${ }^{1}$, Hadiyanto $^{2}$, Rusdinal ${ }^{3}$, Sulastri ${ }^{4}$ Keterkaitan Iklim Organisasi Dengan Faktor Lainnya

\begin{tabular}{|l|l|l|l|l|}
\hline NO & \multicolumn{1}{|c|}{ Sumber } & \multicolumn{1}{|c|}{$\begin{array}{c}\text { Hubungan/ } \\
\text { Pengaruh }\end{array}$} & $\begin{array}{r}\text { Variabel } \\
\text { dependen }\end{array}$ & Koefisien \\
\hline 1. & $\begin{array}{l}\text { Artikel (Machwati \& } \\
\text { Wibowo, 2015) }\end{array}$ & Budaya Kerja & Iklim Organisasi & 0,241 \\
\hline
\end{tabular}

Berikut ini disajikan rekapitulasi hasil penelitian oleh para peneliti terkait dengan hubungan, pengaruh, ataupun kontribusi faktor komunikasi interpersonal terhadap iklim organisasi, dalam bentuk tabel sebagai berikut :

Tabel 7. Pengaruh Komunikasi Interpersonal terhadap Iklim Organisasi

\begin{tabular}{|l|l|l|l|l|}
\hline NO & \multicolumn{1}{|c|}{ Sumber } & \multicolumn{1}{|c|}{$\begin{array}{c}\text { Hubungan/ } \\
\text { Pengaruh }\end{array}$} & $\begin{array}{r}\text { Variabel } \\
\text { dependen }\end{array}$ & \multicolumn{1}{c|}{ Koefisien } \\
\hline 1. & $\begin{array}{l}\text { Artikel (Azrimul \& } \\
\text { Masyhuri, 2015) }\end{array}$ & Komunikasi Interpersonal & Iklim Organisasi & 0,754 \\
\hline
\end{tabular}

Berikut ini disajikan rekapitulasi hasil penelitian oleh para peneliti terkait dengan hubungan, pengaruh, ataupun kontribusi faktor komitmen terhadap iklim organisasi, dalam bentuk tabel sebagai berikut:

Tabel 8. Pengaruh Komitmen terhadap Iklim Organisasi

\begin{tabular}{|l|l|l|l|l|}
\hline NO & \multicolumn{1}{|c|}{ Sumber } & \multicolumn{1}{|c|}{$\begin{array}{c}\text { Hubungan/ } \\
\text { Pengaruh }\end{array}$} & $\begin{array}{c}\text { Variabel } \\
\text { dependen }\end{array}$ & Koefisien \\
\hline 1. & $\begin{array}{l}\text { Artikel (Machwati \& } \\
\text { Wibowo, 2015) }\end{array}$ & Komitmen & Iklim Organisasi & 0,409 \\
\hline
\end{tabular}

\subsection{Pembahasan}

\subsubsection{Tabel Faktor-Faktor yang dipengaruhi oleh Iklim Organisasi}

\begin{tabular}{|l|l|l|}
\hline NO & Faktor yang dipengaruhi & Jumlah artikel \\
\hline 1. & Kepuasan kerja & 10 \\
\hline 2. & Kinerja karyawan & 7 \\
\hline 3. & Motivasi kerja & 2 \\
\hline
\end{tabular}

Pada tabel ini dipaparkan bahwasannya beberapa ahli mengatakan banyak faktor yang dipengaruhi Iklim Organisasi yang ditemukan dalam penelitian ini adalah Kepuasan Kerja mengenai factor yang dipengaruhi oleh iklim organisasi terdapat tiga aspek yang ditelaah yakni terkait kepuasan kerja, kinerja karyawan dan motivasi kerja.

\subsubsection{Faktor-Faktor yang mempengaruhi Iklim Organisasi}

Pada faktor yang mempengaruhi iklim organisasi ini terdapat pula beberapa aspek yang dapat dilihat yakni : a) Gaya Kepemimpinan dengan Iklim Organisasi, b) Budaya Organisasi dengan Iklim Organisasi, c) Komunikasi Interpersonal dengan Iklim Organisasi, d) Komitmen Guru dengan Iklim Organisasi. Beberapa ahli juga mengatakan banyak faktor yang mempengaruhi Iklim Organisasi, akan tetapi dalam penelusuran artikel ditemukan faktor yang sedikit berbeda dengan pendapat para ahli. Faktor yang mempengaruhi Iklim yaitu Gaya Kepemimpinan, Budaya Organisasi, Budaya Kerja, Komunikasi Interpersonal dan Komitmen

Dari data hasil penelusuran artikel faktor yang mempengaruhi Iklim organisasi dan faktor yang dipengaruhi Iklim Organisasi, dapat digambarkan sebagai berikut:

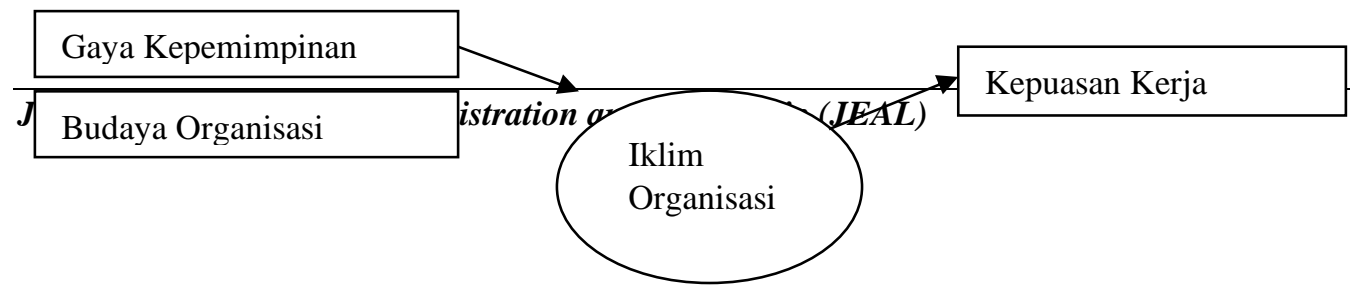




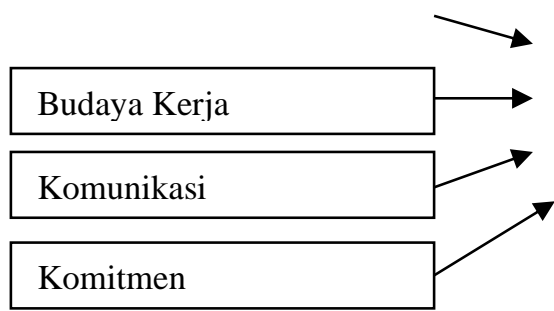

Kinerja karyawan

Motivasi Kerja

\section{Kesimpulan dan Saran}

Kesimpulan

Beberapa ahli mengatakan banyak faktor yang dipengaruhi Iklim Organisasi yang ditemukan dalam penelitian ini faktor-faktor yang dipengaruhi Iklim Organisasi adalah Kepuasan Kerja, Kinerja dan Motivasi kerja karyawan. Sedangkan, Beberapa ahli juga mengatakan banyak faktor yang mempengaruhi Iklim Organisasi, akan tetapi dalam penelusuran artikel ditemukan faktor yang sedikit berbeda dengan pendapat para ahli. Faktor yang mempengaruhi Iklim yaitu Gaya Kepemimpinan, Budaya Organisasi, Budaya Kerja, Komunikasi Interpersonal dan Komitmen

Saran

Disarankan kepada pimpinan organisasi atau sekolah agar senantiasa mempertahnkan atau memperbaiki iklim organisasi dengan optimal karena iklim organisasi mempengaruhi atau berkorelasi dengan variabel-variabel lainnya. Di samping itu harus pula diperbaiki faktor-faktor lainnya yang mempengaruhi iklim organisasi karena iklim organisasi tersebut jug amempengaruhi faktor-faktor lain.

Daftar Rujukan

Abdillah, M. R., Anita, R., \& Anugerah, R. (2017). Dampak Iklim Organisasi Terhadap Stres Kerja Dan Kinerja Karyawan. Jurnal Manajemen, 20(1), 121. https://doi.org/10.24912/jm.v20i1.69

Amri, Abidin, \& Nurmayanti. (2017). Pengaruh Gaya Kepemimpinan Transformasional terhadap Organizational Citizenship Behavior dengan Iklim Organisasi sebagai Variabel Intervening (Studi pada Kantor Dukcapil Kota Mataram). Jurnal Magister Manajemen, 6(2000), 1-14.

Azrimul, \& Masyhuri. (2015). Hubungan Antara Komunikasi Interpersonal dengan Iklim Organisasi pada Pegawai SMA Negeri 1 XII Koto Kampar Kabupaten Kampar-Riau. Menara, 12(1).

Etty Susanty. (2012). Pengaruh iklim organisasi terhadap kepuasan kerja dan komitmen karyawan pada universitas terbuka. Jurnal Organisasi Dan Manajemen, 8, 121-134.

Hadiyanto. (2016). Teori dan Pengembangan Iklim Kelas dan Iklim Sekolah. Jakarta: Kencana.

Hermawan, G. (2016). Hubungan Iklim Organisasi Dengan Kepuasan Kerja Karyawan Pt. Jembayan Muarabara Desa Separi Tenggarong Seberang. Psikoborneo, 4(2), 374-383. https://doi.org/10.17509/gea.v9i1.1674

Janah, R., Akbar, Z., \& Yetti, E. (2019). Pengaruh Iklim Organisasi terhadap Kinerja Guru PAUD di Kota Depok. Jurnal Obsesi : Jurnal Pendidikan Anak Usia Dini, 4(1), 234. https://doi.org/10.31004/obsesi.v4i1.236

Lagonah, Pio, \& Kaunang. (2016). Pengaruh Iklim Organisasi dan Budaya Organisasi terhadap Kepuasan Kerja Pegawai Kantor Pertahanan Kota Manado. Ilimiah Society, 1(24).

Liana, Y. (2012). IKLIM ORGANISASI DAN MOTIVASI BERPRESTASI TERHADAP KEPUASAN KERJA DAN KINERJA GURU Yuyuk Liana STIE Malangkucecwara Malang. Jurnal Manajemen Dan Akuntansi, 1(2), 15-30. Retrieved from http://publishing-widyagama.ac.id/ejournal-v2/index.php/jma/article/view/285

Machwati, A., \& Wibowo, U. B. (2015). Pengaruh Budaya Kerja, Komitmen, Motivasi Kerja Guru Terhadap Iklim Organisasi Sd. Jurnal Akuntabilitas Manajemen Pendidikan, 3(2), 156-172. https://doi.org/10.21831/amp.v3i2.6333 
Mahendra, I. K., \& Subudi, M. (2019). Pengaruh Iklim Organisasi Dan Sistem Reward Terhadap Kepuasan Kerja Dan Komitmen Organisasional Pada Cv. Wiracana. E-Jurnal Ekonomi Dan Bisnis Universitas Udayana, 4, 395. https://doi.org/10.24843/eeb.2019.v08.i04.p04

Maria Rini Kustrianingsih, Maria Magdalena Minarsih, L. B. H. (2016). Pengaruh Motivasi Kerja, Kepemimpinan dan Iklim Organisasi terhadap Kinerja Karyawan Pada Dinas Kebudayaan dan Pariwisata Kota Semarang. Management, 02(02), 1-13.

Nabilah, F. P., Tewal, B., \& Trang, I. (2017). Pengaruh Pelatihan, Pendidikan Dan Iklim Organisasi Terhadap Kepuasan Kerja Karyawan Pada Pt. Pln (Persero) Sektor Pembangkitan Minahasa. Jurnal EMBA: Jurnal Riset Ekonomi, Manajemen, Bisnis Dan Akuntansi, 5(2), 1882-1890. https://doi.org/10.35794/emba.v5i2.16460

Ni Komang Enny Trisnayanti, A. G. R. (2017). Pengaruh Gaya Kepemimpinan Demokratis terhadap Iklim Organisasi dan Kualitas Kehidupan Kerja Karyawan. Jurnal Ilmu Manajemen (JUIMA), 7(2). Retrieved from https://jurnal.unmas.ac.id/index.php/JUIMA/article/view/867/798

Ni Luh Putu Suarningsih. (2013). Pengaruh Iklim Organisasi terhadap Komitmen Organisasional dan Kinerja Karyawan di Rumah Sakit. Jurnal Aplikasi Manajemen, 11(2), 233-240. Retrieved from https://jurnaljam.ub.ac.id/index.php/jam/article/view/565/575

Pamungkas, W., \& Jabar, C. S. A. (2014). Pengaruh Profesionalitas, Kepuasan Kerja Dan Iklim Organisasi Terhadap Kinerja Guru Smkn Di Kabupaten Boyolali. Jurnal Akuntabilitas Manajemen Pendidikan, 2(2), 265-278. https://doi.org/10.21831/amp.v2i2.2454

Pratiwi, H. (2016). Pengaruh Kepemimpinan, Iklim Organisasi, Dan Budaya Kerja Terhadap Motivasi Kerja Dalam Meningkatkan Kinerja Pegawai Pt. Admiral Lines Belawan. Jurnal Bis-A: Jurnal Bisnis Administrasi, 5(2), 42-48. Retrieved from http://ejurnal.plm.ac.id/index.php/BIS-A/article/view/155/137

Radianto, Ari. Sunuharyo, B. (2017). Pengaruh iklim organisasi dan budaya organisasi terhadap kinerja karyawan ( Studi pada Karyawan PT . PG Krebet Baru Malang ). Jurnal Administrasi Bisnis, 53(1), 14-20. Retrieved from

https://www.google.com/url?sa=t\&rct=j\&q=\&esrc=s\&source=web\&cd=\&cad=rja\&uact=8\&ved=2ahUKE wiaks_42ersAhXWXisKHeDhDnwQFjAAegQIBRAC\&url=http\%3A\%2F\%2Fadministrasibisnis.studentj ournal.ub.ac.id\%2Findex.php\%2Fjab\%2Farticle\%2Fview\%2F2177\&usg=AOvVaw1ODCkaJK-gYLCSB

Rahmawati, S., \& Supartha, W. G. (2015). KEPUASAN KERJA PEGAWAI BALAI WILAYAH SUNGAI BALI - PENIDA Fakultas Ekonomi dan Bisnis Universitas Udayana ( Unud ), Bali , Indonesia Fakultas Ekonomi dan Bisnis Universitas Udayana ( Unud ), Bali , Indonesia ABSTRAK PENDAHULUAN Pegawai negeri sipil yang b. E-Journal Manajemen Unud, 4(11), 3405-3437.

Salianto, \& Lubis, R. (2014). Hubungan Gaya Kepemimpinan Spiritual Dan Budaya. Analitika, 6(1), 16-26.

Sari, E. (2009). Pengaruh Kompensasi dan Iklim Organisasi terhadap Kepuasan Kerja. Jurnal ILmu Aministrasi Dan Organisasi, 16(1), 18-24.

Subawa, I., \& Surya, I. (2017). Pengaruh Iklim Organisasi Dan Stres Kerja Terhadap Kepuasan Kerja Guru Sma 1 Gianyar. E-Jurnal Manajemen Universitas Udayana, 6(4), 244584.

Suliman, A., \& B. A. Harethi. (2013). Perceived work climate and employee performance in public security organizations in the UAE. Transforming Goverment: People, Procces and Policy, 7(3), 410-424.

Surachim, A. (2008). Pengaruh Iklim Organisasi Terhadap Kepuasan Kerja Karyawan Pada Divisi Pharmaserve Di Pt Combiphar Jakarta. Strategic: Jurnal Pendidikan Manajemen Bisnis, 8(1), 58. https://doi.org/10.17509/strategic.v8i1.1005

Susanty, E. (2012). Pengaruh Iklim Organisasi Terhadap Kepuasan Kerja dan Komitmen Karyawan Pada Universitas Terbuka. Jurnal Organisasi Dan Manajemen, 8(2), 121-134.

Syahril, Hadiyanto, Adi, N., \& Irsyad. (2017). Pengembangan dan Pemvalidasian Alat Ukur serta Perbaikan Iklim 
Sisy Maharani ${ }^{1}$, Hadiyanto $^{2}$, Rusdinal ${ }^{3}$, Sulastri ${ }^{4}$ Keterkaitan Iklim Organisasi Dengan Faktor Lainnya

Sekolah Menengah Pertama di Sumatera Barat. Padang.

Wahyudi, H., \& Dewi, A. S. (2019). Pengaruh Iklim Organisasi Terhadap Motivasi Kerja Pegawai Pada Pt. Bank Mandiri Kc Lapangan Imam Bonjol Padang. 1-9. https://doi.org/10.31219/osf.io/45x92

Widyo Aryanto, R., Siti Astuti, E., \& Kumadji, S. (2019). PENGARUH BUDAYA ORGANISASI TERHADAP IKLIM ORGANISASI DAN KEPUASAN KERJA (Kajian pada Karyawan Koperasi Grup Cipta Sejahtera). Profit, 13(02), 23-28. https://doi.org/10.21776/ub.profit.2019.013.02.3

Wirawan. (2008). Budaya dan Iklim Organisasi. Jakarta: Salemba Empat. 